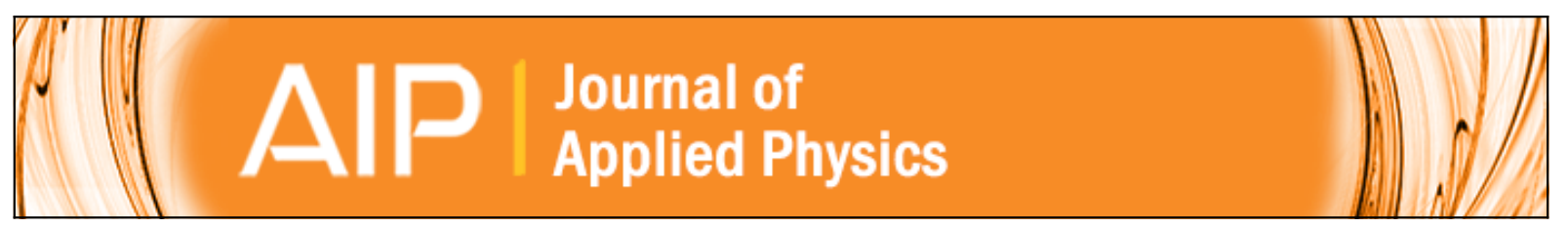

\title{
Tunable magnetocaloric effect in Gd-based glassy ribbons
}

Charlotte Mayer, Stéphane Gorsse, Geraldine Ballon, Rafael Caballero-Flores, Victorino Franco, and Bernard Chevalier

Citation: Journal of Applied Physics 110, 053920 (2011); doi: 10.1063/1.3632983

View online: http://dx.doi.org/10.1063/1.3632983

View Table of Contents: http://scitation.aip.org/content/aip/journal/jap/110/5?ver=pdfcov

Published by the AIP Publishing

\section{Articles you may be interested in}

Theoretical description of magnetocaloric effect in the shape memory alloy exhibiting metamagnetic behavior J. Appl. Phys. 119, 013902 (2016); 10.1063/1.4939556

Entropy change of a Ni45.5Co4.5Mn37ln 13 single crystal studied by scanning calorimetry in high magnetic fields: Field dependence of the magnetocaloric effect

Appl. Phys. Lett. 107, 092403 (2015); 10.1063/1.4929950

The magnetocaloric effect and critical behavior in amorphous Gd60Co40-xMnx alloys

J. Appl. Phys. 111, 07A922 (2012); 10.1063/1.3673860

Magnetocaloric effects in RNiln ( $\mathrm{R}=\mathrm{Gd}-\mathrm{Er})$ intermetallic compounds

J. Appl. Phys. 109, 123926 (2011); 10.1063/1.3603044

Magnetocaloric effect in ribbon samples of Heusler alloys Ni-Mn-M ( M = In , Sn )

Appl. Phys. Lett. 97, 212505 (2010); 10.1063/1.3521261

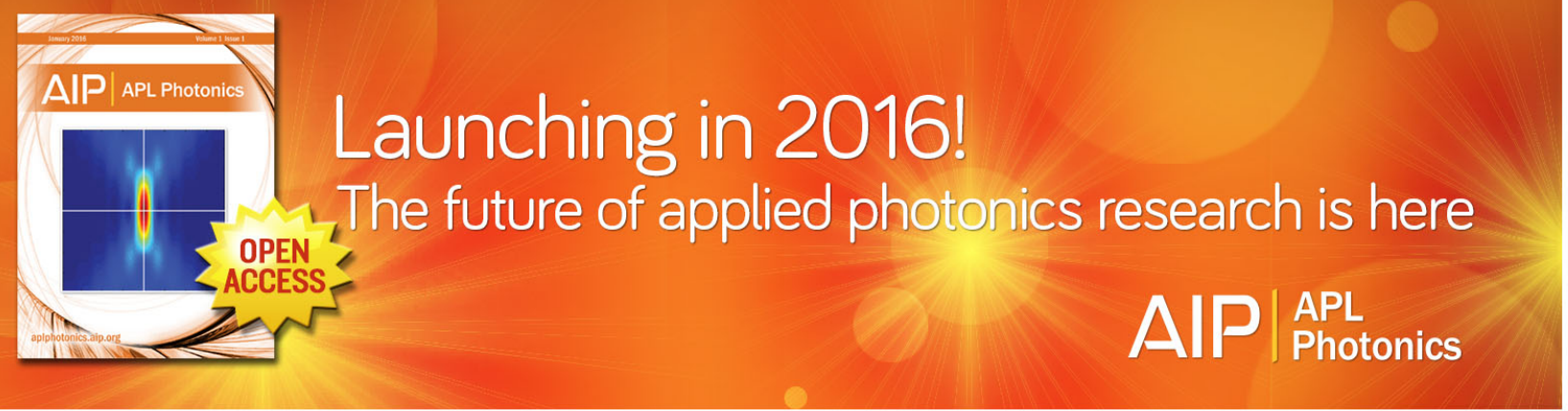




\title{
Tunable magnetocaloric effect in Gd-based glassy ribbons
}

\author{
Charlotte Mayer, ${ }^{1}$ Stéphane Gorsse, ${ }^{1,2, a)}$ Geraldine Ballon, ${ }^{3}$ Rafael Caballero-Flores, ${ }^{4}$ \\ Victorino Franco, ${ }^{4}$ and Bernard Chevalier ${ }^{1}$ \\ ${ }^{1}$ CNRS, Université de Bordeaux, ICMCB, 87 Avenue du Docteur Albert Schweitzer, 33608 Pessac Cedex, \\ France \\ ${ }^{2} I P B, E N S C B P, 16$ Avenue Pey-Berland, 33607 Pessac, France \\ ${ }^{3}$ LNCMI-T, UPR 3228, CNRS-UJF-UPS-INSA, 143 Avenue de Rangueil, 31400 Toulouse, France \\ ${ }^{4}$ Departamento de Fisica de la Materia Condensada, ICMSE-CSIC, Universidad de Sevilla, P. O. Box 1065 , \\ 41080 Sevilla, Spain
}

(Received 19 May 2011; accepted 31 July 2011; published online 15 September 2011)

\begin{abstract}
The series of glassy ribbons $\mathrm{Gd}_{60} M_{30} \mathrm{In}_{10}(M=\mathrm{Mn}, \mathrm{Co}, \mathrm{Ni}, \mathrm{Cu})$ was synthesized by melt-spinning. The change of transition element $M$ in these Gd-based metallic glasses was proven to induce huge variations of the Curie temperature $\mathrm{T}_{\mathrm{C}}$, magnetic entropy change peak values $\Delta \mathrm{S}_{\mathrm{m}}{ }^{\text {peak }}$, and widths at half maximum values of the magnetic entropy change $\delta \mathrm{T}$. When $M$ is non magnetic $(M=\mathrm{Co}$, $\mathrm{Ni}, \mathrm{Cu}$ ), the samples behave similarly: they display high values of $\Delta \mathrm{S}_{\mathrm{m}}{ }^{\text {peak }}$ (between -6.6 and -8.2 $\mathrm{J} / \mathrm{kg} \mathrm{K}$ in a magnetic field variation of $4.6 \mathrm{~T}$ ), average $\delta \mathrm{T}$ values (between 77 and $120 \mathrm{~K}$ ) and no magnetic hysteresis. On the contrary, when $M$ carries a magnetic moment $(M=\mathrm{Mn})$, some irreversibility appears at low temperature, $\Delta \mathrm{S}_{\mathrm{m}}{ }^{\text {peak }}$ is lower (only $3.1 \mathrm{~J} / \mathrm{kg} \mathrm{K}$ for $\mu_{0} \mathrm{H}=4.6 \mathrm{~T}$ ) and the magnetic transition is very large $\left(\delta \mathrm{T}=199 \mathrm{~K}\right.$ for $\left.\mu_{0} \mathrm{H}=4.6 \mathrm{~T}\right)$. These features are explained by some antiparallel coupling between $\mathrm{Mn}$ atoms randomly located in the metallic glass. This leads to the occurrence of a cluster-glass behavior at low temperature $(35 \mathrm{~K})$, following the ferromagnetic transition observed at $180 \mathrm{~K}$ when the temperature is decreased. Also, power law fittings of $\Delta \mathrm{S}_{\mathrm{m}}{ }^{\text {peak }}$ and $\delta \mathrm{T}$ versus $\mu_{0} \mathrm{H}$ were performed and show that $\delta \mathrm{T}$ is less field dependent than $\Delta \mathrm{S}_{\mathrm{m}}{ }^{\text {peak }}$. We could then identify an interesting way of improving the refrigeration capacity of the material at low magnetic field. (C) 2011 American Institute of Physics. [doi:10.1063/1.3632983]
\end{abstract}

\section{INTRODUCTION}

With the increasing need for energy efficient and environmentally friendly technologies, the search for new magnetocaloric materials (MCM) suitable for magnetic refrigeration has grown considerably in the last ten years. ${ }^{1-10}$ This technology exploits the magnetocaloric effect (MCE), which is the adiabatic temperature change (or isothermal magnetic entropy change) of a magnetic material when subjected to a varying magnetic field. In addition to their expected reduced environmental impact, by avoiding the use of gases enhancing the greenhouse effect used in conventional compression-expansion cycles, magnetic refrigerators are expected to reach higher performances. ${ }^{11}$

A large MCE is associated to a large change in magnetization close to the magnetic ordering temperature of the material. According to the type of magnetic transition that they undergo, two types of MCM can be distinguished. It is either a first order magneto-structural phase transition (FOMT) or a second order magnetic phase transition (SOMT). In FOMT materials, the magnetization shows an abrupt variation at the magnetic ordering temperature and the coincidence of magnetic and structural transitions leads to the so-called giant magnetocaloric effect (GMCE) (of which the compound $\mathrm{Gd}_{5} \mathrm{Si}_{2} \mathrm{Ge}_{2}$ is the most famous example) characterized by a very narrow and large peak of isothermal magnetic entropy

\footnotetext{
a) Author to whom correspondence should be addressed. Fax: +3354000 6321. Electronic mail: gorsse@icmcb-bordeaux.cnrs.fr.
}

change $\Delta \mathrm{S}_{\mathrm{m}}^{\text {peak }}{ }^{1}$ This is associated to undesirable thermal and magnetic hysteresis that must be reduced to use these materials for magnetic refrigeration. Some very promising works has already been done in that sense. ${ }^{12}$ SOMT materials (usually ferromagnetic materials) are characterized by the absence of thermal and magnetic hysteresis, with gradual and continuous magnetization variation at the magnetic ordering temperature. They also display smaller but broader $\Delta \mathrm{S}_{\mathrm{m}}(\mathrm{T})$, resulting in competitive refrigerant capacities ( $\mathrm{RC}$, defined as the area under $\Delta \mathrm{S}_{\mathrm{m}}(\mathrm{T})$ curve with temperatures at half maximum value of the peak as integration boundaries). Pure gadolinium is the typical example of SOMT materials; and because its Curie temperature $\left(T_{C}=293 \mathrm{~K}\right)$ is close to room temperature and it exhibits a large $\mathrm{MCE}$, it is still today the material of choice to investigate the efficiency of experimental magnetic refrigerators. ${ }^{13,14}$ However, the low abundance, high price and easy corrosion of $\mathrm{Gd}$ make it unlikely to be used as such on an industrial production scale. One way of elaborating new MCM is then to work on Gdbased metallic glasses. ${ }^{8,15-24}$ It allows maintaining a high density of magnetic moments and no magnetic hysteresis while decreasing the content of expensive $\mathrm{Gd}$ and overcomes the issue of easy corrosion. These materials also display good mechanical properties ${ }^{25}$ and a low electric resistivity that decreases eddy current losses. By comparing many different studies, it is shown, ${ }^{8,15-24}$ that changing the transition element $M$ of metallic glasses in the Gd-RE- $M$-Al systems, with $R E=$ Rare Earth, allowed the tuning of the magnetocaloric properties. In the present study, the model 


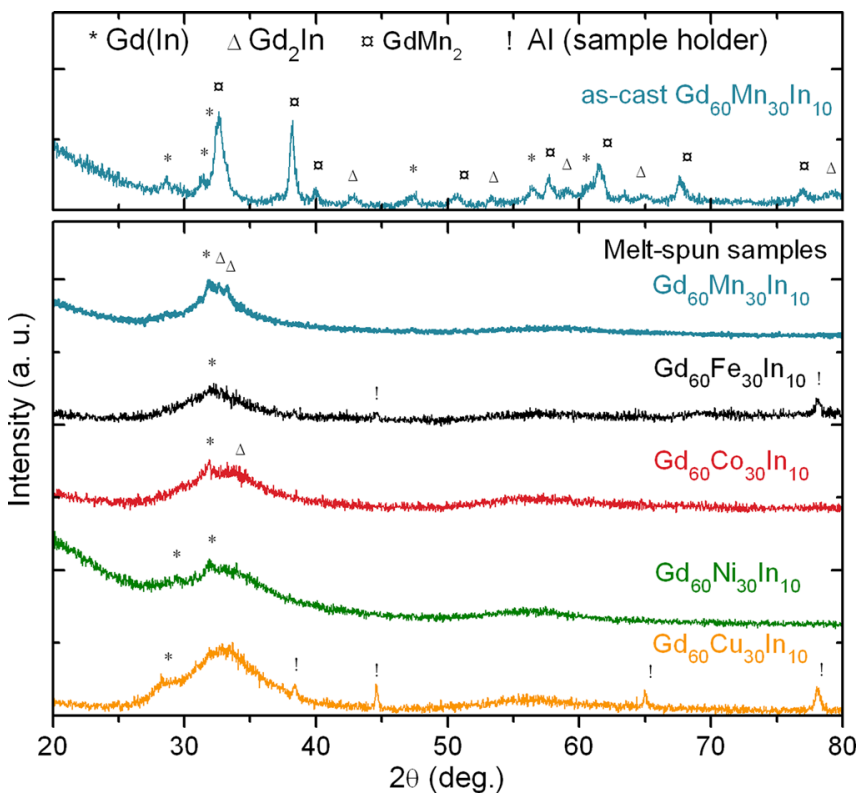

FIG. 1. (Color online) X-ray diffraction patterns of as-cast $\mathrm{Gd}_{60} \mathrm{Mn}_{30} \mathrm{In}_{10}$ (upper part) and melt-spun $\mathrm{Gd}_{60} M_{30} \mathrm{In}_{10}, M=\mathrm{Mn}, \mathrm{Fe}, \mathrm{Co}, \mathrm{Ni}$, and $\mathrm{Cu}$ (lower part). The phases are identified by symbols as indicated on top of the patterns.

composition of $\mathrm{Gd}_{60} M_{30} \operatorname{In}_{10}$ metallic glasses, with $M=\mathrm{Mn}$, $\mathrm{Fe}, \mathrm{Co}, \mathrm{Ni}$, and $\mathrm{Cu}$, was chosen to study the properties arising from the change of $M$ element. The $\mathrm{Gd}_{60} M_{30} \mathrm{In}_{10}$ composition was determined on the basis of topologic and thermodynamic criteria described elsewhere ${ }^{26,27}$ to ensure a good glass forming ability. The use of In as p-element instead of $\mathrm{Al}$ was proven to slightly increase the Curie temperature of these mid-range $\mathrm{T}_{\mathrm{C}}$ glassy ribbons as recently reported for the $\mathrm{Gd}_{60} \mathrm{Mn}_{30} X_{10}$ composition with $X=\mathrm{Al}$, Ga and In. ${ }^{28}$

In this paper, we report the structural, magnetic, and magnetocaloric properties of $\mathrm{Gd}_{60} M_{30} \mathrm{In}_{10}$ glassy ribbons with $M=\mathrm{Mn}, \mathrm{Fe}, \mathrm{Co}, \mathrm{Ni}$, and $\mathrm{Cu}$ and discuss the properties of these materials in comparison to those observed previously for samples in the Gd-RE-M-Al systems. In a second part, a particular attention is given to $\mathrm{Gd}_{60} \mathrm{Mn}_{30} \mathrm{In}_{10}$ meltspun ribbons, which display cluster-glass behavior at low temperature.

\section{EXPERIMENTAL}

Alloys with the following nominal compositions (at.\%), $\mathrm{Gd}_{60} M_{30} \mathrm{In}_{10}$ with $M=\mathrm{Mn}, \mathrm{Fe}, \mathrm{Co}, \mathrm{Ni}$, and $\mathrm{Cu}$, were prepared by melting precisely weighted amounts of high purity elements (at least 99.9\%) in a levitation furnace. Melting in a water cooled copper crucible, under a purified argon atmosphere was performed several times to ensure a good homogeneity. The weight loss during the overall melting process was less than $0.1 \mathrm{wt} . \%$ for each alloy. Glassy ribbons of these as-cast samples were then obtained by single roller melt-spinning technique with a copper wheel velocity between 25 and $30 \mathrm{~ms}^{-1}$, also in a purified argon atmosphere.

The structural properties were checked on both sides of the ribbons by X-ray diffraction (XRD) using a Philips PW
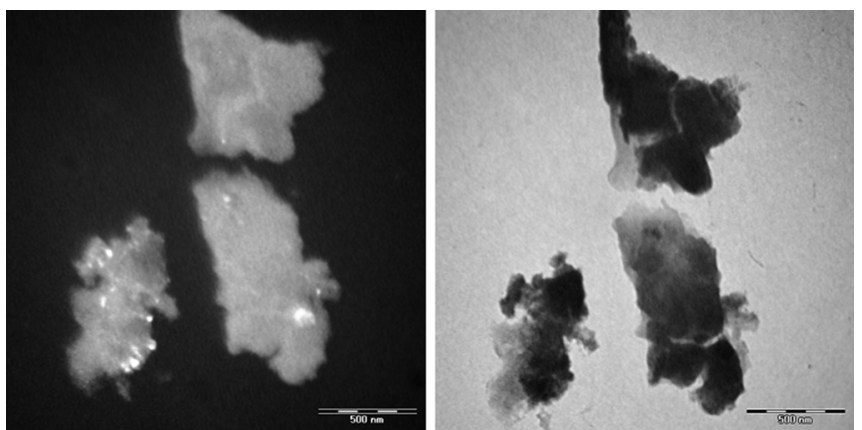

FIG. 2. TEM dark and white field micrographs of a fragment of melt-spun $\mathrm{Gd}_{60} \mathrm{Mn}_{30} \mathrm{In}_{10}$ ribbons showing nanocrystallites embedded in the amorphous matrix.

PANalytical X'Pert MDP with $\mathrm{Cu} \mathrm{K} \alpha$ radiation. Transmission electron microscopy (TEM) with a JEOL JEM 2000 FX apparatus was also used to observe the nanocrystallites in the melt-spun $\mathrm{Gd}_{60} \mathrm{Mn}_{30} \mathrm{In}_{10}$. dc and ac magnetization measurements were done on ribbons milled in powder, using a QD MPMS (SQUID) in the temperature range of 5-300 K and applied fields up to $4.6 \mathrm{~T}$. Magnetization measurements were performed using the compensated coil technique in pulsed magnetic fields up to $53 \mathrm{~T}$ at the LNCMI-Toulouse.

\section{RESULTS AND DISCUSSION}

\section{Magnetic and magnetocaloric properties}

$\mathrm{X}$-ray powder diffraction investigations performed on $\mathrm{Gd}_{60} M_{30} \mathrm{In}_{10}$ as-cast samples reveal the presence of several compounds in good agreement with the ternary Gd- $M$-In ternary phase diagrams. For instance, the upper part of Fig. 1 shows that the as-cast $\mathrm{Gd}_{60} \mathrm{Mn}_{30} \mathrm{In}_{10}$ is composed of three compounds: the solid solution $\operatorname{Gd}(\operatorname{In}),{ }^{29}$ the binary phases $\mathrm{Gd}_{2} \mathrm{In}^{30}$ and $\mathrm{GdMn}_{2}$ doped by In. ${ }^{31}$

The bottom part of Fig. 1 shows the XRD patterns of melt-spun $\operatorname{Gd}_{60} M_{30} \mathrm{In}_{10}$ ribbons. The two broad halos centered around $2 \theta=32^{\circ}$ and $58^{\circ}$, detected on these patterns,

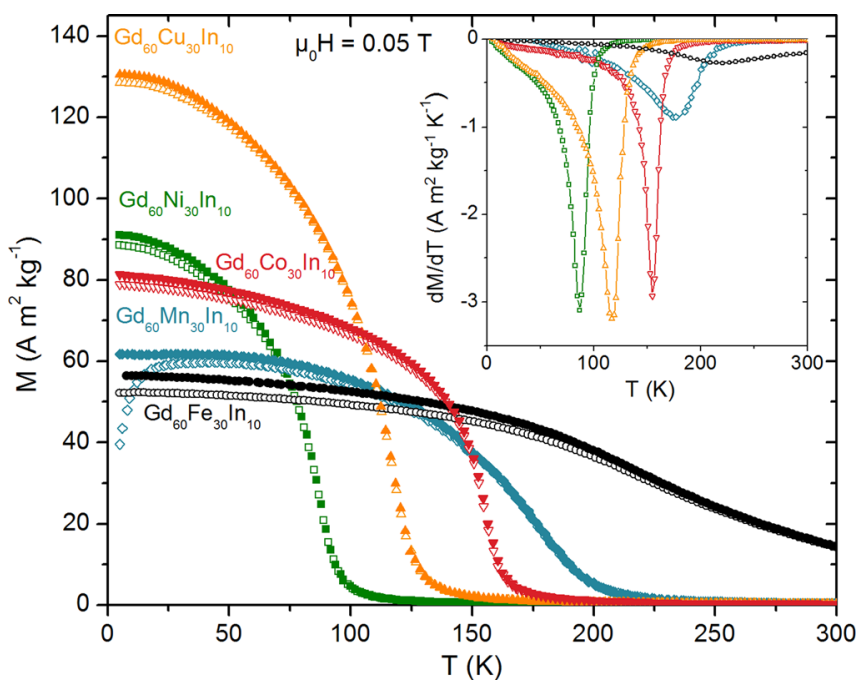

FIG. 3. (Color online) Temperature dependence of the magnetization $\mathrm{M}$ (zero-field-cooled (open symbols) and field-cooled (full symbols) measurements) of the $\mathrm{Gd}_{60} M_{30} \mathrm{In}_{10}$ melt-spun samples, with an applied field of 0.05 $\mathrm{T}$. The inset shows the derivative $\mathrm{dM} / \mathrm{dT}$ vs $\mathrm{T}$ curves. 
TABLE I. Curie temperatures $\mathrm{T}_{\mathrm{C}}$, temperatures of peak of magnetic entropy change $\mathrm{T}_{\mathrm{pk}}$, maximum of magnetic entropy change $\Delta \mathrm{S}_{\mathrm{m}}$ peak , full width at half maximum of the magnetic entropy change peak $\delta \mathrm{T}$, and refrigeration capacity $\mathrm{RC}$ of the glassy ribbons and pure $\mathrm{Gd}$ at $4.6 \mathrm{~T} . \Delta \mathrm{S}_{\mathrm{m} / \mathrm{Gd}}{ }^{\text {peak }}$ and $\mathrm{RC} / \mathrm{Gd}$ are the values of the maximum magnetic entropy change and refrigeration capacity per weight of Gd, respectively.

\begin{tabular}{lcccccccc}
\hline \hline Composition & $\mathrm{T}_{\mathrm{C}}(\mathrm{K})$ & $\mathrm{T}_{\mathrm{pk}}(\mathrm{K})$ & $\Delta \mathrm{S}_{\mathrm{m}}^{\text {peak }}(\mathrm{J} / \mathrm{kg} \mathrm{K})$ & $\Delta \mathrm{S}_{\mathrm{m} / \mathrm{Gd}}{ }^{\text {peak }}(\mathrm{J} / \mathrm{kg}(\mathrm{Gd}) \mathrm{K})$ & $\delta \mathrm{T}(\mathrm{K})$ & $\mathrm{RC}(\mathrm{J} / \mathrm{kg})$ & $\mathrm{RC}_{/ \mathrm{Gd}}(\mathrm{J} / \mathrm{kg}(\mathrm{Gd})$ & $\mathrm{Reference}$ \\
\hline $\mathrm{Gd}_{60} \mathrm{Mn}_{30} \mathrm{In}_{10}$ & 180 & 192.5 & -3.1 & -4.0 & 199 & 466 & 563 \\
$\mathrm{Gd}_{60} \mathrm{Co}_{30} \mathrm{In}_{10}$ & 159 & 161 & -7.7 & -10.1 & 77 & 406 & 616 \\
$\mathrm{Gd}_{60} \mathrm{Ni}_{30} \mathrm{In}_{10}$ & 86 & 89.5 & -8.2 & -10.8 & 96 & 602 & 780 \\
$\mathrm{Gd}_{60} \mathrm{Cu}_{30} \mathrm{In}_{10}$ & 115 & 120 & -6.6 & -8.7 & 120 & 598 & 877 \\
Pure Gd & 293 & - & $-9.2^{\mathrm{a}}$ & $-9.2^{\mathrm{a}}$ & $73^{\mathrm{a}}$ & $503^{\mathrm{a}}$ & $503^{\mathrm{a}}$ & $\mathrm{This}$ \\
\hline \hline
\end{tabular}

${ }^{a}$ Values obtained by interpolating the data from Ref. 34 for $4.6 \mathrm{~T}$.

are characteristic of amorphous structures. These $2 \theta$ positions are comparable to those reported for the $\mathrm{Gd}_{60} M_{30} \mathrm{Al}_{10}$ melt-spun samples with $M=\mathrm{Mn}$ and Co. ${ }^{16,22}$ But some very small peaks reveal the presence of nanocrystallites of the two Gd-rich phases, $\mathrm{Gd}(\mathrm{In})$ and $\mathrm{Gd}_{2} \mathrm{In}$, also evidenced in the as-cast samples. Figure 2 displays TEM bright and dark field micrographs of $\mathrm{Gd}_{60} \mathrm{Mn}_{30} \mathrm{In}_{10}$ crushed ribbons. The bright field micrograph (on the right side of Fig. 2) shows the pieces of crushed ribbons. Nanocrystallites of size between 10 and $100 \mathrm{~nm}$ are then visible in white on the dark field micrograph (on the left of Fig. 2).

Figure 3 shows the temperature dependence of the zerofield-cooled (ZFC) and field-cooled (FC) magnetization $M$ of melt-spun $\mathrm{Gd}_{60} M_{30} \mathrm{In}_{10}$ samples, measured with an applied field of $0.05 \mathrm{~T}$. All samples show some irreversibility between ZFC and FC curves and this behavior is much more pronounced in the case of $\mathrm{Gd}_{60} \mathrm{Mn}_{30} \mathrm{In}_{10}$. A similar result was previously evidenced for the $\mathrm{Gd}_{60} \mathrm{Mn}_{30} \mathrm{Al}_{10}$ metallic glasses. ${ }^{16}$ The large and slow increase in magnetization, visible for each sample with decreasing temperature, is characteristic of a structurally disordered phase and is usually attributed to the ferromagnetic ordering of the clusters constituting the amorphous matrix. ${ }^{32}$ The Curie temperatures, $\mathrm{T}_{\mathrm{C}}$, of these melt-spun samples are given in Table I and were defined as the extrema of the derivative $\mathrm{dM} / \mathrm{dT}$ versus $\mathrm{T}$ curves presented in the inset of Fig. 3. They range from $86 \mathrm{~K}$

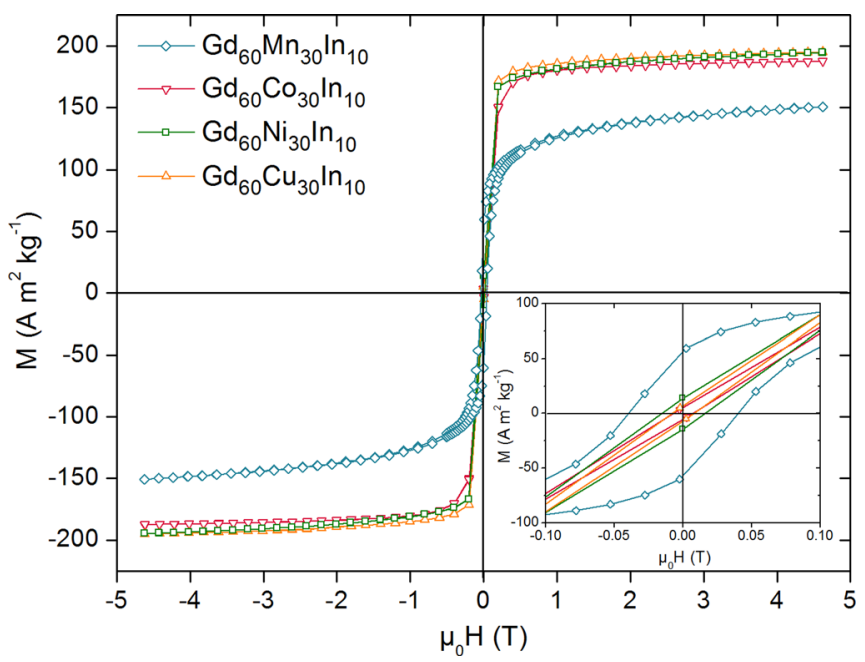

FIG. 4. (Color online) Field dependence between -4.6 and $4.6 \mathrm{~T}$ and at $5 \mathrm{~K}$, of the magnetization $\mathrm{M}$ of melt-spun ribbons $\mathrm{Gd}_{60} M_{30} \mathrm{In}_{10}, M=\mathrm{Mn}, \mathrm{Co}, \mathrm{Ni}$, and $\mathrm{Cu}$. The inset presents a zoom showing the coercive field and remanence of the samples. with $M=\mathrm{Ni}$, to $180 \mathrm{~K}$ with $M=\mathrm{Mn}$. It is also worth noticing that no other magnetic transitions attributable to the nanocrystallites detected by X-ray diffraction are visible on the magnetization versus $\mathrm{T}$ curves.

Also, even at $300 \mathrm{~K}$, above its $\mathrm{T}_{\mathrm{C}}=200 \mathrm{~K}$, the magnetization of $\mathrm{Gd}_{60} \mathrm{Fe}_{30} \mathrm{In}_{10}$ takes a higher value than the expected for a paramagnetic state only (Fig. 3). This feature reveals the probable presence of another magnetic phase with higher $\mathrm{T}_{\mathrm{C}}$ in the material.

The huge influence of the transition element $M$ on the metallic glasses $T_{C}$ is probably connected to the nature of the indirect Ruderman-Kittel-Kasuya-Yosida (RKKY) magnetic interactions that govern the magnetic properties of intermetallics based on rare earth like gadolinium. These interactions depend locally on the Gd-Gd interatomic distances and on the number of conduction electrons; two parameters changing with the nature of $M 3 d$ transition metal. We also notice that a comparable evolution of $\mathrm{T}_{\mathrm{C}}$ is observed for the $\mathrm{Gd}_{60} M_{30} \mathrm{Al}_{10}$ metallic glasses since this temperature is equal to 171,143 , and $80 \mathrm{~K}$ for $\mathrm{Gd}_{60} \mathrm{Mn}_{30} \mathrm{Al}_{10}{ }^{28}$ $\mathrm{Gd}_{60} \mathrm{Co}_{30} \mathrm{Al}_{10},{ }^{22}$ and $\mathrm{Gd}_{55} \mathrm{Ni}_{25} \mathrm{Al}_{20},{ }^{24}$ respectively.

Magnetization versus the applied magnetic field $\mu_{0} \mathrm{H}$ isotherms were measured at $5 \mathrm{~K}$, between -4.6 and $4.6 \mathrm{~T}$ on $\mathrm{Gd}_{60} M_{30} \mathrm{In}_{10}$ ribbons (Fig. 4). Samples with $M=\mathrm{Co}, \mathrm{Ni}$ and

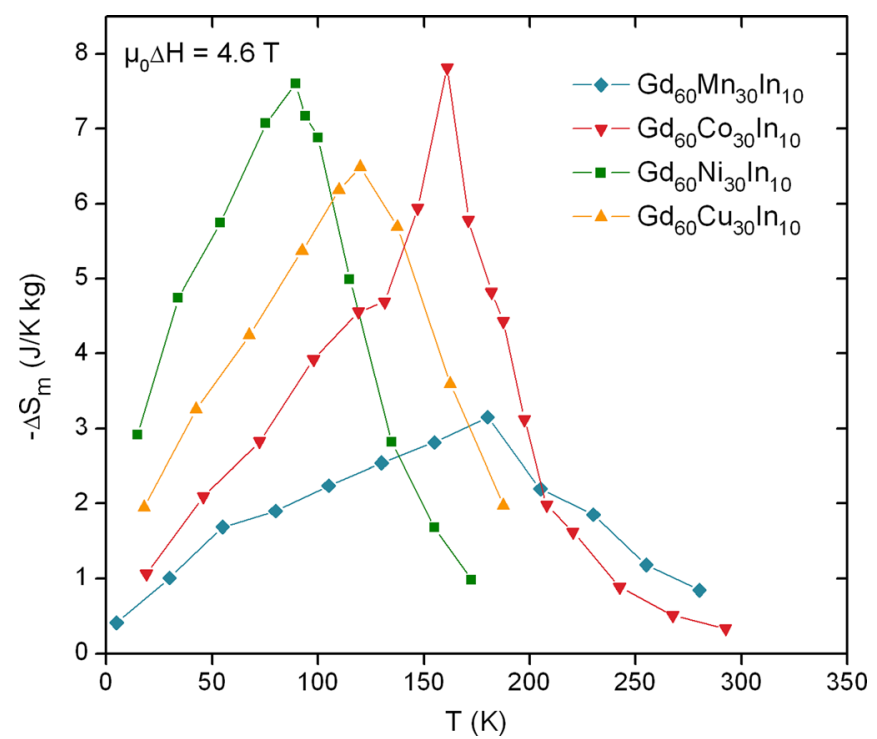

FIG. 5. (Color online) Temperature dependence of the isothermal magnetic entropy change $\Delta \mathrm{S}_{\mathrm{m}}$ with a magnetic field change of $4.6 \mathrm{~T}$, of melt-spun ribbons $\mathrm{Gd}_{60} M_{30} \mathrm{In}_{10}, M=\mathrm{Mn}, \mathrm{Co}, \mathrm{Ni}$, and $\mathrm{Cu}$. 
$\mathrm{Cu}$ do not show any noticeable hysteresis, contrary to $\mathrm{Gd}_{60} \mathrm{Mn}_{30} \mathrm{In}_{10}$ that displays a remanence of $56 \mathrm{~A} \mathrm{~m}^{2} \mathrm{~kg}^{-1}$ and a coercivity of $0.039 \mathrm{~T}$ (inset of Fig. 4). Still, its energy loss during cycling of $24.7 \mathrm{~J} \mathrm{~kg}^{-1}$, is negligible.

Isothermal field dependence of $\mathrm{M}$ was measured between 0 and $4.6 \mathrm{~T}$, for various temperatures between 5 and $300 \mathrm{~K}$. These $\mathrm{M}$ versus $\mu_{0} \mathrm{H}$ curves allow calculating the isothermal magnetic entropy change $\Delta S_{\mathrm{m}}$ by integrating the Maxwell relationship: ${ }^{33}$

$$
\Delta S_{m}=\mu_{0} \int_{H_{0}}^{H_{f}}\left(\frac{\partial M(T, H)}{\partial T}\right)_{H} d H .
$$

The resulting $\Delta \mathrm{S}_{\mathrm{m}}$ versus $\mathrm{T}$ plots, in a magnetic field variation of 4.6 T, are reported in Fig. 5. All samples show broad peaks centered near their $\mathrm{T}_{\mathrm{C}}$ as measured by magnetization measurements. For $\mu_{0} \mathrm{H}=4.6 \mathrm{~T}$, the $\Delta \mathrm{S}_{\mathrm{m}}$ peak values for $M=\mathrm{Co}, \mathrm{Ni}$, and $\mathrm{Cu}$, lie between $72 \%$ and $89 \%$ of that of pure Gd (Ref. 34) and twice as less for $M=\mathrm{Mn}$ (value per total mass of sample). Still, the very large $\delta \mathrm{T}$ values of all samples, and especially for $\mathrm{Gd}_{60} \mathrm{Mn}_{30} \mathrm{In}_{10}$, lead to $\mathrm{RC}$ values that compete with pure Gd and are even higher in the cases of $\mathrm{Gd}_{60} \mathrm{Ni}_{30} \mathrm{In}_{10}$ and $\mathrm{Gd}_{60} \mathrm{Cu}_{30} \mathrm{In}_{10}$ glassy ribbons. Let us notice in Table I, that, if we express these values per mass of $\mathrm{Gd}$, the melt-spun ribbons compare very favorably to pure $\mathrm{Gd}$. When compared per mass of $\mathrm{Gd}, \Delta \mathrm{S}_{\mathrm{m}}{ }^{\text {peak }} / \mathrm{Gd}$ and $\mathrm{RC}_{/ \mathrm{Gd}}$ for the ribbons are much better than pure Gd but their $\mathrm{T}_{\mathrm{C}}$ is smaller.

Figure 6 shows the evolutions of $\Delta \mathrm{S}_{\mathrm{m}}{ }^{\text {peak }} / \mu_{0} \Delta \mathrm{H}$ and $\delta \mathrm{T} /$ $\mu_{0} \Delta \mathrm{H}$ versus $\mathrm{T}_{\mathrm{C}}$ with data for Gd-based metallic glasses. As these $\Delta \mathrm{S}_{\mathrm{m}}{ }^{\text {peak }}$ and $\delta \mathrm{T}$ values come from various studies with different magnetic field used, it is necessary to remove this field effect. They are then divided by the applied field $\mu_{0} \Delta \mathrm{H}$ on Fig. 6. A first observation is that these two values have opposite evolutions with increasing $\mathrm{T}_{\mathrm{C}}$, and this will induce a limit to the achievable $\mathrm{RC}$ in these Gd-based metallic glasses. The second noticeable trend is that the metallic glasses with a given $M$ metal have a tendency to regroup themselves. This confirms the huge impact of the $M$ element on the magnetic properties of Gd-RE-M-X metallic glasses, with $R E=$ rare earth, $M=\mathrm{Mn}, \mathrm{Fe}, \mathrm{Co}, \mathrm{Ni}$, and $\mathrm{Cu}$, and $X=\mathrm{Al}$, In, and $\mathrm{Ga}$.

A second order magnetic transition can be described by some critical exponents in the vicinity of its critical (a)

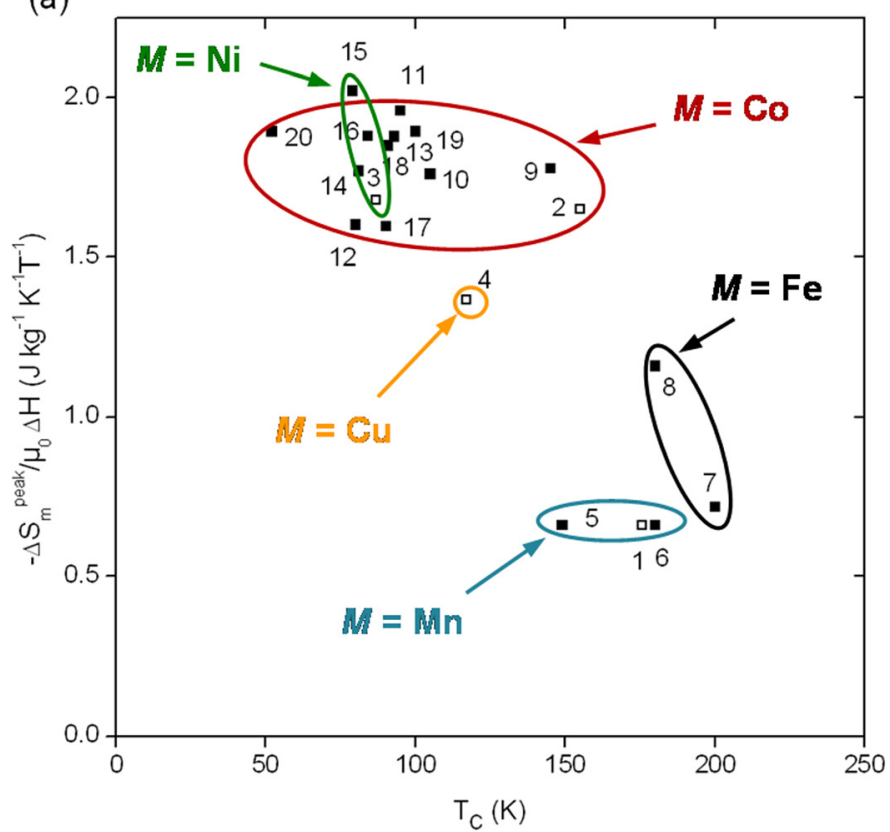

1- $\mathrm{Gd}_{60} \mathrm{Mn}_{30} \mid \mathrm{n}_{10}$ (this work)

2- $\mathrm{Gd}_{60} \mathrm{Co}_{30} \mathrm{In}_{10}$ (this work)

3- $\mathrm{Gd}_{60} \mathrm{Ni}_{30} \ln _{10}$ (this work)

4- $\mathrm{Gd}_{60} \mathrm{Cu}_{30} / \mathrm{n}_{10}$ (this work)

5- $\mathrm{Gd}_{60} \mathrm{Mn}_{30} \mathrm{Al}_{10}$ [16]

6- $\mathrm{Gd}_{60} \mathrm{Mn}_{30} \mathrm{Ga}_{10}[28]$

7- $\mathrm{Gd}_{60} \mathrm{Fe}_{30} \mathrm{Al}_{10}$ [20] (b)

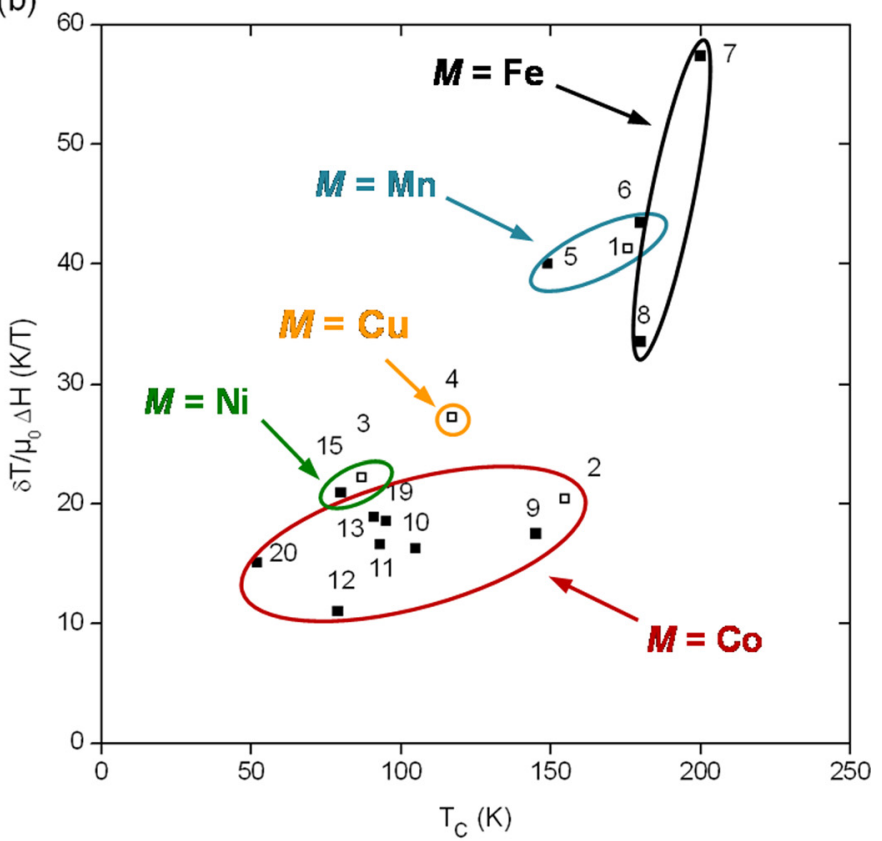

15- $\mathrm{Gd}_{55} \mathrm{Ni}_{25} \mathrm{Al}_{20}$ [8]

16- $\mathrm{Gd}_{48} \mathrm{Al}_{25} \mathrm{Co}_{20} \mathrm{Zr}_{3} \mathrm{Er}_{4}$ [21]

17- $\mathrm{Gd}_{51} \mathrm{Al}_{24} \mathrm{Co}_{20} \mathrm{Nb}_{1} \mathrm{~B}_{4}$ [21]

18- $\mathrm{Gd}_{51} \mathrm{Al}_{24} \mathrm{Co}_{20} \mathrm{Zr}_{4} \mathrm{Nb}_{1}$ [21]

19- $\mathrm{Gd}_{51} \mathrm{Al}_{24} \mathrm{Co}_{20} \mathrm{Nb}_{1} \mathrm{Cr}_{4}$ [21]

20- $\mathrm{Gd}_{33} \mathrm{Er}_{22} \mathrm{Al}_{25} \mathrm{Co}_{20}$ [15]

FIG. 6. (Color online) Maximal value of isothermal magnetic entropy change divided by the magnetic field change $-\Delta \mathrm{S}_{\mathrm{m}}{ }^{\text {peak }} / \mu_{0} \Delta \mathrm{H}$ (a) and temperature width at half maximum value of the magnetic entropy change divided by the magnetic field variation $\delta \mathrm{T} / \mu_{0} \Delta \mathrm{H}$ (b) vs $\mathrm{T}_{\mathrm{C}}$ of melt-spun ribbons $\mathrm{Gd}_{60} M_{30} \mathrm{In}_{10}, M=\mathrm{Mn}_{\text {, }}$ $\mathrm{Co}, \mathrm{Ni}$, and $\mathrm{Cu}$ (empty squares) and $\mathrm{Gd}-$ based metallic glasses from the literature (full squares). 
TABLE II. Fitting parameters $\mathrm{n}$ and $\mathrm{m}$ of $\Delta \mathrm{S}_{\mathrm{m}}^{\text {peak }} \alpha\left(\mu_{0} \mathrm{H}\right)^{\mathrm{n}}$ and $\delta \mathrm{T} \alpha$ $\left(\mu_{0} \mathrm{H}\right)^{\mathrm{m}}$ power laws

\begin{tabular}{lllc}
\hline \hline Composition & $\mathrm{n}$ & $\mathrm{m}$ & Reference \\
\hline $\mathrm{Gd}_{60} \mathrm{Mn}_{30} \mathrm{In}_{10}$ & 0.91 & 0.22 & This work \\
$\mathrm{Gd}_{60} \mathrm{Co}_{30} \mathrm{In}_{10}$ & 0.92 & 0.16 & This work \\
$\mathrm{Gd}_{60} \mathrm{Ni}_{30} \mathrm{In}_{10}$ & 0.83 & 0.26 & This work \\
$\mathrm{Gd}_{60} \mathrm{Cu}_{30} \mathrm{In}_{10}$ & 0.80 & 0.30 & This work \\
Pure Gd & $0.74^{\mathrm{a}}$ & $0.47^{\mathrm{a}}$ & 34 \\
\hline
\end{tabular}

${ }^{a}$ Values obtained by interpolating the data from Ref. 34.

temperature $\left(T_{C}\right)$. These will lead to the establishment of different classes of materials of which magnetic behaviors are governed by power laws with the same critical exponents. ${ }^{35}$ The power law fittings $\Delta S_{m}^{p e a k} \alpha\left(\mu_{0} H\right)^{n}$ were performed on the magnetic data of $\mathrm{Gd}_{60} M_{30} \mathrm{In}_{10}$. These fittings of the experimental values led to the $n$ exponents shown in Table II. They are different from the $2 / 3$ expected from the mean field model for SOMT materials. ${ }^{36}$ This model does not apply to these materials. Recently, Franco et al. have found, for $\mathrm{Fe}_{\mathrm{x}} \mathrm{Co}_{\mathrm{y}} \mathrm{B}_{\mathrm{z}} \mathrm{CuSi}_{3} \mathrm{Al}_{5} \mathrm{Ga}_{2} \mathrm{P}_{10}$ (Ref. 37) and $\mathrm{Fe}_{73.2} \mathrm{Pd}_{26.8}$ (Ref. 38) glassy ribbons, field independent $n$ exponents of 0.75 and 0.83 , respectively, for the magnetic field dependence of $\Delta \mathrm{S}_{\mathrm{m}}$ peak . The $n$ exponents of $\mathrm{Gd}_{60} M_{30} \mathrm{In}_{10}$ glassy ribbons are larger and lie between 0.80 and 0.92 , suggesting that their critical behaviors are different from those of $\mathrm{Fe}$ based amorphous ribbons. They are also different from that of pure $\mathrm{Gd}$ as $n=0.74$ for this material. ${ }^{34}$

The fittings of $\delta T \alpha\left(\mu_{0} H\right)^{m}$ were also performed and the very small values of $m$ exponents show that $\delta$ T is not much dependent on the applied field compared to $\Delta \mathrm{S}_{\mathrm{m}}{ }^{\text {peak }}$. Figure 7 describes this assumption by showing $\delta \mathrm{T}$ versus $-\Delta \mathrm{S}_{\mathrm{m}}{ }^{\text {peak }}$ between 1.4 and $4.6 \mathrm{~T}$, for $\mathrm{Gd}_{60} M_{30} \mathrm{In}_{10}$ melt-spun ribbons and pure $\mathrm{Gd}$. The slope of $\delta \mathrm{T}$ versus $-\Delta \mathrm{S}_{\mathrm{m}}{ }^{\text {peak }}$ clearly decreases when $\mu_{0} \Delta \mathrm{H}$ increases. So to improve the $\mathrm{RC}$ of a

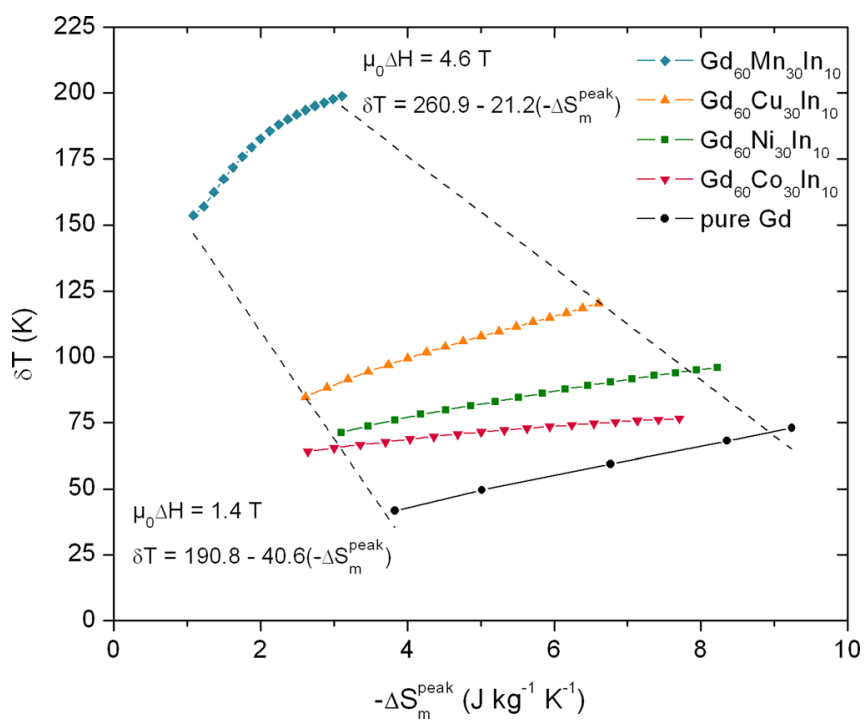

FIG. 7. (Color online) Temperature width at half maximum value of the magnetic entropy change $\delta \mathrm{T}$ vs $-\Delta \mathrm{S}_{\mathrm{m}}{ }^{\text {peak }}$, the maximum of isothermal magnetic entropy change, between 1.4 and $4.6 \mathrm{~T}$, for melt-spun ribbons $\mathrm{Gd}_{60} M_{30} \mathrm{In}_{10}$ and pure Gd. Dotted lines represent linear fittings of $\delta \mathrm{T}$ vs $\Delta \mathrm{S}_{\mathrm{m}}^{\text {peak }}$ at 1.4 and $4.6 \mathrm{~T}$.

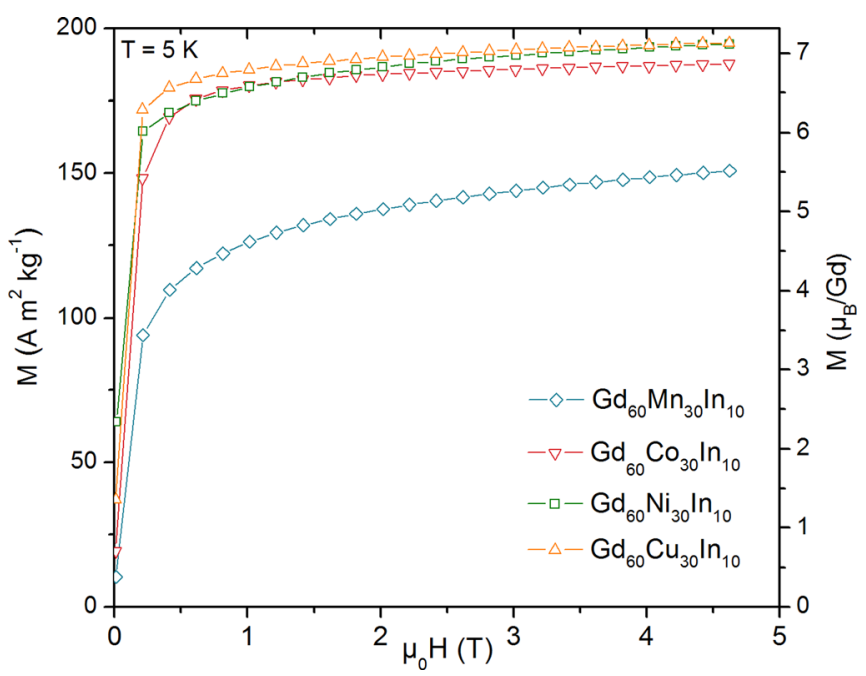

FIG. 8. (Color online) Field dependence of the magnetization $\mathrm{M}$ at $5 \mathrm{~K}$, between 0 and $4.6 \mathrm{~T}$ of melt-spun $\mathrm{Gd}_{60} M_{30} \mathrm{In}_{10}, M=\mathrm{Mn}, \mathrm{Co}, \mathrm{Ni}$, and $\mathrm{Cu}$.

given glassy ribbon with a given $\Delta \mathrm{S}_{\mathrm{m}}{ }^{\text {peak }}$ value, in the low magnetic field range, it appears very valuable to increase $\delta$ T.

\section{Low temperature cluster-glass behavior of melt-spun $\mathrm{Gd}_{60} \mathrm{Mn}_{30} \mathrm{In}_{10}$}

At $5 \mathrm{~K}$, magnetization versus $\mu_{0} \mathrm{H}$ curves (Fig. 8) show that $\mathrm{Gd}_{60} M_{30} \mathrm{In}_{10}$ samples with $M=\mathrm{Co}, \mathrm{Ni}$, and Cu quickly reach saturation near $7 \mu_{\mathrm{B}} / \mathrm{Gd}$, corresponding to the magnetic moment expected for a ferromagnet based on Gd. The glassy ribbons with $M=\mathrm{Mn}$ behave differently: the increase of magnetization is very low with increasing $\mu_{0} \mathrm{H}$ and it does not saturate in a field of $4.6 \mathrm{~T}$, the maximum magnetic moment reached being only $5.5 \mu_{\mathrm{B}} / \mathrm{Gd}$. Magnetization measurements at a higher applied field, of $55 \mathrm{~T}$, (Fig. 9) were performed on $\mathrm{Gd}_{60} \mathrm{Mn}_{30} \mathrm{In}_{10}$ ribbons to verify if any saturation could occur in this material; and on $\mathrm{Gd}_{60} \mathrm{Co}_{30} \mathrm{In}_{10}$ for comparison. $\mathrm{Gd}_{60} \mathrm{Co}_{30} \mathrm{In}_{10}$ sample reaches a very fast saturation near $7 \mu_{\mathrm{B}} / \mathrm{Gd}$ and thus confirms the previous measurements performed at 4.6 T. Increasing the applied field allowed $\mathrm{Gd}_{60} \mathrm{Mn}_{30} \mathrm{In}_{10}$ ribbons to attain a maximal value of magnetic moment of $6.9 \mu_{\mathrm{B}} / \mathrm{Gd}$. This higher field constrained the sample to a further order but still, this ordering remains very slow and saturation is not reached.

These observations, in addition to the previously reported low temperature irreversibility of $\mathrm{M}$ versus $\mathrm{T}$ for $\mathrm{Gd}_{60} \mathrm{Mn}_{30} \mathrm{In}_{10}$ (Fig. 3), suggest spin-glass-like behavior occurring at low temperature, in this material. ${ }^{39,40}$

Since the 70th, ac susceptibility measurements are used to study spin-glass-like transitions. Indeed, applying a sinusoidal magnetic field to a magnetic material, at a given frequency, will induce a magnetic answer also sinusoidal. This magnetic answer will be as much out of phase as the relaxation times of the system are long. The real part of ac susceptibility, $\chi^{\prime}$ is in phase with the applied magnetic field whereas the imaginary part $\chi^{\prime \prime}$ is in quadrature with it. ac susceptibility measurements were performed on both $\mathrm{Gd}_{60} \mathrm{Mn}_{30} \mathrm{In}_{10}$ and $\mathrm{Gd}_{60} \mathrm{Co}_{30} \mathrm{In}_{10}$ (Fig. 10) to investigate their different behaviors at low temperature. A dc-field of $100 \mathrm{Oe}$ 


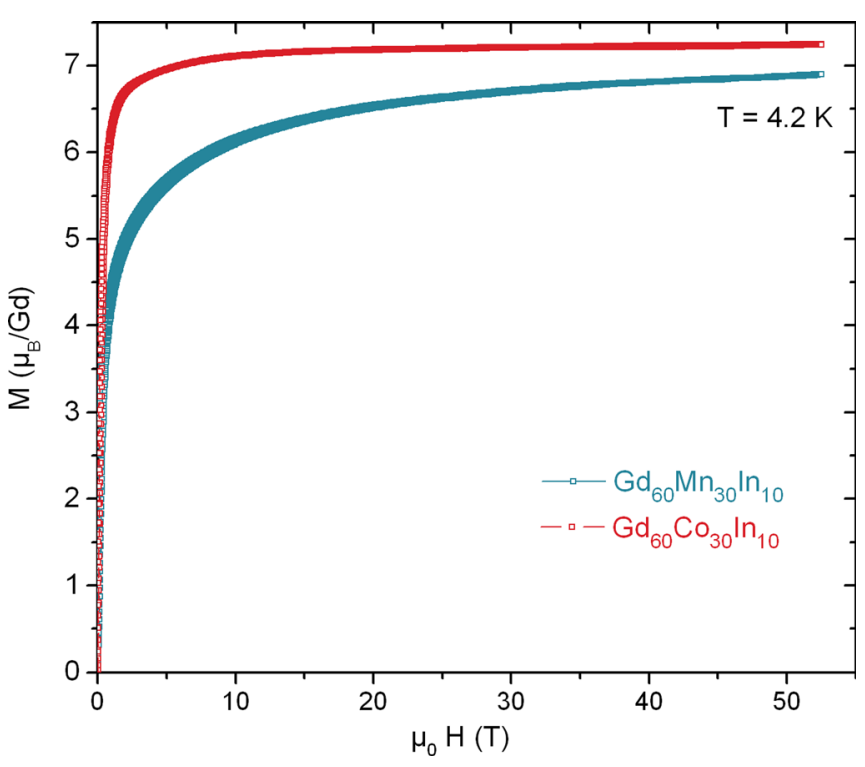

FIG. 9. (Color online) Field dependence of the magnetization $\mathrm{M}$ at $4.2 \mathrm{~K}$, between 0 and $55 \mathrm{~T}$ of melt-spun $\mathrm{Gd}_{60} \mathrm{Mn}_{30} \mathrm{In}_{10}$ and $\mathrm{Gd}_{60} \mathrm{Co}_{30} \mathrm{In}_{10}$.

was applied and an ac-field of 2 Oe varying with frequencies ranging from 1.25 to $1250 \mathrm{~Hz}$ were used, thereby permitting a full determination of the real $\chi^{\prime}$ and imaginary $\chi^{\prime \prime}$ parts. At $177 \mathrm{~K}$, both $\chi^{\prime}$ and $\chi$ ' of $\mathrm{Gd}_{60} \mathrm{Mn}_{30} \mathrm{In}_{10}$ show the ferromagnetic to paramagnetic transition already observed with dc magnetization measurements. When the temperature is further decreased, both the drop of $\chi$ ' and the occurrence of a peak on $\chi$ " near $27 \mathrm{~K}$ are observed. The $\chi$ " part characterizes the dynamics of the system. The apparition of this peak is linked to the establishment of a magnetic order in the material that will dissipate some energy because of the alternating nature of the applied magnetic field. This dissipation gets larger when the frequency is increased. The resulting peak is then the indication of the freezing of magnetic clusters ${ }^{39}$ in
$\mathrm{Gd}_{60} \mathrm{Mn}_{30} \mathrm{In}_{10}$ (Fig. 10(a)) that will resist to the alternative variation of the field. These features are those of clusterglass (re-entrant spin-glass) magnetism, characterized by magnetic relaxation phenomena when entering into the low temperature cluster-glass state from a higher temperature ferromagnetic state. ${ }^{40}$

In the case of amorphous materials, the critical slowing down observed close to the re-entrant temperature $\mathrm{T}_{\mathrm{RSG}}$ presents a difficult quantitative evaluation compared to canonical spin-glasses as it reflects the behavior of several clusters that vary in size and probably in composition. Still, an approximated $\mathrm{T}_{\mathrm{RSG}}$ of $35 \mathrm{~K}$ was determined, according to Mydosh, ${ }^{39}$ as the maximum slope of the $\chi$ " peak attributed to the cluster glass transition; given that the two peaks of cluster glass and ferromagnetic transitions cannot be well separated on the $\chi$ ' curve.

All the observations made on the ac susceptibility curves of $\mathrm{Gd}_{60} \mathrm{Mn}_{30} \mathrm{In}_{10}$ suggesting its cluster glass behavior at low temperature are absent of that of $\mathrm{Gd}_{60} \mathrm{Co}_{30} \mathrm{In}_{10}$, only the ferromagnetic ordering at $155 \mathrm{~K}$ is visible (Fig. 10(b)). This proves that the cluster-glass behavior is induced by the presence of $\mathrm{Mn}$ atoms in the metallic glass. Indeed, at such a concentration of $\mathrm{Mn}$ atoms, the statistical chance of one $\mathrm{Mn}$ atom being first or second nearest neighbor to another $\mathrm{Mn}$ atom is considerable and short range negative interactions between $\mathrm{Mn}$ atoms occur, as described by Obi et al. in amorphous Mn-Y alloys. ${ }^{41}$ Small randomly oriented magnetic clusters then form at low temperature as a result of concentration fluctuation in such a disordered material. This type of spin-glass-like behavior is the first to be shown in a Gdbased metallic glass. Spin glass behavior in rare earth based metallic glasses is usually observed when the rare-earth introduces some random magnetic anisotropy, due to spinorbit coupling, that pins the magnetic moments according to the local structural anisotropies as in the case of $\mathrm{Tb}$ based $^{42,43}$ and Nd-based ${ }^{44}$ metallic glasses.
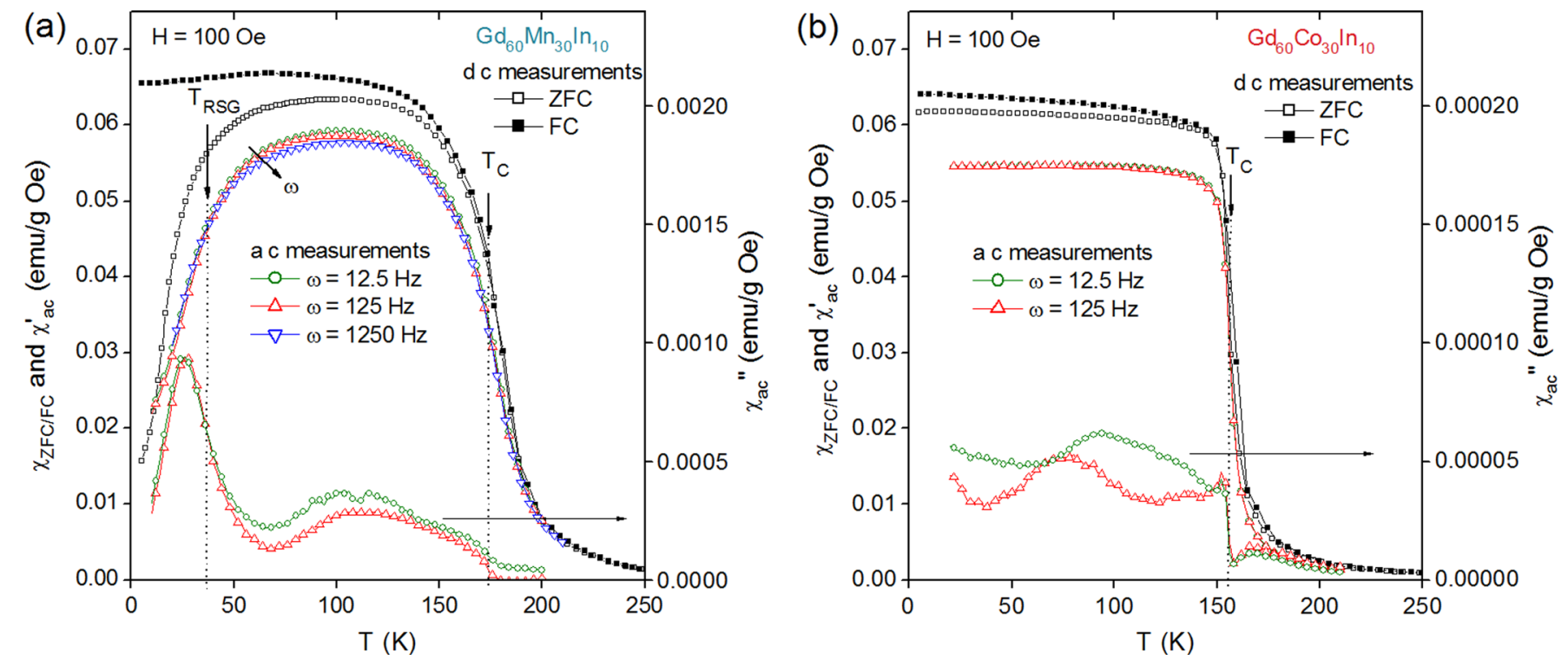

FIG. 10. (Color online) ac susceptibility measurements with a dc-field of 100 Oe and an ac-field change of 2 Oe with frequencies of 12.5 , 125 , and $1250 \mathrm{~Hz}$, for $\mathrm{Gd}_{60} \mathrm{Mn}_{30} \mathrm{In}_{10}$ (a) and 12.5 and $125 \mathrm{~Hz}$, for $\mathrm{Gd}_{60} \mathrm{Co}_{30} \mathrm{In}_{10}$ (b). 


\section{CONCLUSION}

The series of glassy ribbons $\mathrm{Gd}_{60} M_{30} \mathrm{In}_{10}, M=\mathrm{Mn}, \mathrm{Fe}$, $\mathrm{Co}, \mathrm{Ni}$, and $\mathrm{Cu}$ was synthesized by single-roller melt spinning. The $M$ element was proven to have a huge impact on the magnetic and magnetocaloric properties of the materials, with $\mathrm{T}_{\mathrm{C}}$ ranging between 87 and $180 \mathrm{~K} . \Delta \mathrm{S}_{\mathrm{m}}$ globally decreases with $\mathrm{T}_{\mathrm{C}}$ whereas $\delta \mathrm{T}$ increases with $\mathrm{T}_{\mathrm{C}}$, they cannot be both maximized simultaneously and so a choice needs to be made for improving RC. It was also demonstrated that $\delta \mathrm{T}$ is less field dependent than $\Delta \mathrm{S}_{\mathrm{m}}$ and allows one to reach a higher RC with lower magnetic field change. Unfortunately, this is done at the expense of $\Delta \mathrm{S}_{\mathrm{m}}$. Furthermore, materials with higher $\delta \mathrm{T}$ also have higher $\mathrm{T}_{\mathrm{C}}$ and are then closer to the temperature domain of room temperature applications. Finally, the particular magnetic features of $\mathrm{Gd}_{60} \mathrm{Mn}_{30} \mathrm{In}_{10}$ were explained by the existence of a cluster-glass behavior at low temperature due to the antiparallel coupling of $\mathrm{Mn}$ atoms, inexistent with the other $M$ elements of this study.

\section{ACKNOWLEDGMENTS}

The authors are indebted to the Conseil Régional d'Aquitaine for financial support, especially C.M. for a $\mathrm{Ph}$. D. grant and to CNRS through the Research Program "Froid Magnétique" PR08-1.1-6. R.C.F. acknowledges the Regional Government of Andalucia for a research fellowship. Part of this work was supported by EuroMagNET II under the EU Contract No. RII3-CT-2004-506239 and by EGIDE through a bilateral Spanish/French exchange program (FR2009-0101 and 22977TC).

${ }^{1}$ V. K. Pecharsky and K. A. Gschneidner, Phys. Rev. Lett.78, 4494 (1997).

${ }^{2}$ V. K. Pecharsky and K. A. Gschneidner, Adv. Mater. 13, 683 (2001).

${ }^{3}$ H. Wada, K. Morikawa, T. Taniguchi, T. Shibata, Y. Yamada, and Y. Akishige, Physica, B 328, 114 (2003).

${ }^{4}$ O. Tegus, E. Brück, K. H. J. Buschow, and F. R. de Boer, Nature 415, 150 (2002).

${ }^{5}$ A. Fujita, S. Fujieda, Y. Hasegawa, and K. Fukamichi, Phys. Rev. B 67, 104416 (2003)

${ }^{6}$ O. Gutfleisch, A. Yan, and K.-H. Müller, J. Appl. Phys. 97, 10M305 (2005).

${ }^{7}$ T. Krenke, E. Duman, M. Acet, E. F. Wassermann, X. Moya, L. Mañosa, and A. Planes, Nature Mater. 4, 450 (2005).

${ }^{8}$ J. Du, Q. Zheng, Y. B. Li, Q. Zhang, D. Li, and Z. D. Zhang, J. Appl. Phys. 103, 023918 (2008).

${ }^{9}$ R. Caballero-Flores, V. Franco, A. Conde, K. E. Knipling, and M. A. Willard, Appl. Phys. Lett. 96, 182506 (2010).

${ }^{10}$ E. Gaudin, S. Tencé, F. Weill, J. Rodriguez Fernandez, and B. Chevalier, Chem. Mater. 20, 2972 (2008).
${ }^{11}$ C. Zimm, A. Jastrab, A. Sternberg, V. Pecharsky, and K. A. Gschneidner Jr., Adv. Cryog. Eng. 43, 1759 (1998).

${ }^{12}$ J. Lyubina, R. Schäfer, N. Martin, L. Schultz, and O. Gutfleisch, Adv. Mater. 22, 3735 (2010).

${ }^{13}$ Q. Gao, B. F. Yu, C. F. Wang, B. Zhang, D. X. Yang, and Y. Zhang, Int. J. Refrigeration 29, 1274 (2006).

${ }^{14}$ C. Zimm, A. Boeder, J. Chell, A. Sternberg, A. Fujita, S. Fujieda, and K. Fukamichi, Int. J. Refrigeration 29, 1302 (2006).

${ }^{15}$ Q. Luo, D. Q. Zhao, M. X. Pan, and W. H. Wang, Appl. Phys. Lett. 89, 081914 (2006).

${ }^{16}$ S. Gorsse, B. Chevalier, and G. Orveillon, Appl. Phys. Lett. 92, 122501 (2008).

${ }^{17}$ H. Fu, X. Y. Zhang, H. J. Yu, B. H. Teng, and X. T. Zu, Solid State Commun. 145, 15 (2008).

${ }^{18}$ H. Fu, M. S. Guo, H. J. Yu, andcX. T. Zu, J. Magn. Magn. Mater. 321, 3342 (2009).

${ }^{19}$ Q. Y. Dong, B. G. Shen, J. Chen, J. Shen, F. Wang, H. W. Zhang, and J. R. Sun, J. Appl. Phys. 105, 053908 (2009).

${ }^{20}$ B. Schwarz, B. Podmilsak, N. Mattern, and J. Eckert, J. Magn. Magn. Mater. 322, 2298 (2010).

${ }^{21}$ Q. Luo and W. H. Wang, J. Alloys Compd. 495, 209 (2010).

${ }^{22}$ H. Fu and M. Zou, J. Alloys Compd. 509, 4613 (2011).

${ }^{23}$ B. Schwarz, N. Mattern, J. D. Moore, K. P. Skokov, O. Gutfleisch, and J. Eckert, J. Magn. Magn. Mater. 323, 1782 (2011).

${ }^{24}$ J. Chang, X. Hui, Z. Y. Xu, Z. P. Lu, and G. L. Chen, Intermetallics 18, 1132 (2010).

${ }^{25}$ M. F. Ashby and A. L. Greer, Scripta Mater. 54, 321 (2006).

${ }^{26}$ D. Miracle, Nature Mater. 3, 697 (2004).

${ }^{27}$ G. Orveillon, O. N. Senkov, J.-L. Soubeyroux, B. Chevalier, and S. Gorsse, Adv. Eng. Mater. 9, 483 (2007).

${ }^{28}$ C. Mayer, B. Chevalier, and S. Gorsse, J. Alloys Compd. 507, 370 (2010).

${ }^{29}$ W. J. Ren, D. Li, W. Liu, J. Li, and Z. D. Zhang, J. Appl. Phys. 103, $07 \mathrm{~B} 323$ (2008).

${ }^{30}$ A. Palenzona, J. Less-Common Met. 16, 379 (1968).

${ }^{31}$ S. De Negri, D. Kaczorowski, A. Grytsiv, A. Alleno, M. Giovannini, R. Gorzelniak, P. Rogl, C. Godart, A. Saccone, and R. Ferro, J. Alloys Compd. 365, 58 (2004).

${ }^{32}$ X. Y. Liu, J. A. Barclay, R. B. Gopal, M. Földeàki, R. Chahine, T. K. Bose, P. J. Schurer, and J. L. LaCombe, J. Appl. Phys. 79, 1630 (1996).

${ }^{33}$ A. H. Morrish. The Physical Principles of Magnetism (Wiley, New York, 1964).

${ }^{34}$ J. Shen, J.-F Wu, and J.-R. Sun, J. Appl. Phys. 106, 083902 (2009).

${ }^{35}$ H. E. Stanley, Rev. Mod. Phys. 71, S358 (1999).

${ }^{36}$ H. Oesterreicher and F. T. Parker, J. Appl. Phys. 55, 4334 (1984).

${ }^{37}$ V. Franco, J. S. Blásquez, M. Millán, J. M. Borrego, C. F. Conde, and A. Conde, J. Appl. Phys. 101, 09C503 (2007).

${ }^{38}$ V. M. Prida, V. Franco, V. Vega, J. L. Sanchez-Llamazares, J. J. Suñol, A. Conde, and B. Hernando, J. Alloys Compd. 509, 190 (2011).

${ }^{39}$ J. A. Mydosh. Spin Glasses: An Experimental Introduction (Taylor \& Francis, London, 1993).

${ }^{40}$ L. Fernández Barquín, J. C. Gómez Sal, P. Gorria, J. S. Garitaonandia, and J. M. Barandiarán, J. Non-Cryst. Solid 329, 94 (2003).

${ }^{41}$ Y. Obi, S. Murayama, A. Azuma, H. Fujimori, and K. V. Rao, J. Magn. Magn. Mater. 202, 505 (1999).

${ }^{42}$ J. Du, Q. Zheng, E. Bruck, K. H. Buschow, W. B. Cui, W. J. Feng, and Z. D. Zhang, J. Magn. Magn. Mater. 321, 413 (2009).

${ }^{43}$ S. Gorsse, C. Mayer, and B. Chevalier, J. Appl. Phys. 109, 033914 (2011).

${ }^{44}$ S. Gorsse, G. Orveillon, and B. Chevalier, J. Appl. Phys. 103, 044902 (2008). 